\title{
Seismic monitoring by piezoelectric accelerometers of a damaged historical monument in downtown L'Aquila
}

\author{
Giuseppe Di Giulio ${ }^{1,{ }^{\star}}$, Maurizio Vassallo ${ }^{1}$, Giosuè Boscato ${ }^{2}$, Alessandra Dal Cin², Salvatore Russo ${ }^{2}$ \\ ${ }^{1}$ Istituto Nazionale di Geofisica e Vulcanologia, L'Aquila, Italy \\ ${ }^{2}$ IUAV University of Venice, Venice, Italy
}

Article history

Received September 24, 2014; accepted December 18, 2014

Subject classification:

Waves and Wave analysis, Instruments and techniques.

\begin{abstract}
We show the preliminary seismic monitoring of a historical church in L'Aquila (central Italy), which was strongly damaged by the 2009 seismic sequence. This structure, S. Maria del Suffragio church, suffered the collapse of a great part of the dome during the April $6^{\text {th }} 2009 \mathrm{Mw}$ 6.1 earthquake. In this paper, recordings of ambient noise and local earthquakes have been analyzed. The seismic data were recorded by means of a dynamic monitoring system (19 mono-directional and 3 tri-directional piezoelectric accelerometers) and of two velocimeters, with all the instruments installed into the church. The aim of this research is the evaluation of the performance of the accelerometers of the monitoring system in case of low-amplitude vibrations. Simple techniques of analysis commonly employed in the seismic characterization of buildings have been applied. The reliability of the in-situ data was evaluated and the main modal parameters (natural frequencies and damping ratio) of the church were presented.
\end{abstract}

\section{Introduction}

The medieval city of L'Aquila (central Italy), founded in the XIIIth century, is characterized by a significant cultural heritage and several historical earthquakes are documented to cause damages and victims [1315, 1349, 1461 and 1703; Guidoboni 2009 and Tertulliani et al. 2011]. The most recent damaging earthquake was on April 6, 2009, at 01:32 UTC, when a moment magnitude $\left(\mathrm{M}_{\mathrm{w}}\right) 6.1$ event struck central Italy with its epicenter very close to L'Aquila city. The 2009 seismic sequence caused 308 victims, and a macroseismic intensity of VIII-IX for downtown L'Aquila [Galli and Camassi 2009], with some collapses of roofs and domes of important monumental churches [Brandonisio et al. 2013; Gattulli et al. 2013].

Monitoring, performing diagnosis and evaluating the structural dynamic response of important historical structures is essential in such areas at high seismic risk. Many different techniques exist, in time and frequency domain, for deriving indication on the building response by analysis of seismic data. Contrary to techniques based on the analysis of forced vibrations or signals from moderate-to-large earthquakes, techniques based on ambient vibrations consider a low amplitude level of shaking providing indication exclusively in the elastic field [Michel et al. 2008 among many others]. The most basic spectral technique in the building response is the peak picking method [Crawford and Ward 1964; Trifunac 1972], which considers the frequency peaks of the spectra computed for different sensors installed into a structure. In the last decade, seismic interferometry based on the cross-correlation function is also a technique gaining much interest for separating the excitation and the ground coupling from the building response. Seismic interferometry is able to enforce the coherent waves propagating through a structure [Snieder and Şafak 2006].

The case study of our research is Santa Maria del Suffragio (known also as Anime Sante) church situated in downtown L'Aquila. This church was heavily damaged during the 2009 seismic sequence, with the collapse of a great part of the dome and of the tambour. A static and dynamic system of surveillance was adopted in this church [Russo 2012 and 2013; Boscato et al. 2012] for the structural control and health monitoring (from November 2009 to February 2013). Because the dynamic monitoring system was composed of lowcost piezoelectric accelerometers installed inside the structure, we apply seismic techniques for assessing the performance of such accelerometers by using low-amplitude signals.

We analyze ambient vibrations and two local earthquakes (of magnitude 3.6 and 4.8) recorded by the monitoring system, focusing mainly on the dome element. By using low-amplitude vibrations, it is impor- 
tant to check the reliable frequency band provided by the dynamic monitoring. Well-known velocimeters (with eigen-frequency of $0.2 \mathrm{~Hz}$ ) were also used as reference sensors in comparison with the piezoelectric accelerometers. The most rigorous way for investigating the capability of accelerometers is through laboratory tests using a reference sensor and controlled excitations, but in this case study a laboratory test was not possible before the monitoring experiment. The velocimeters allow us to enlarge the frequency band of analysis, evidencing the strong low-frequency resonance (about 0.5 $\mathrm{Hz}$ ) of the subsoil in L'Aquila area, in agreement with the results provided by recent microzoning studies. The results of the seismic monitoring further provide the fundamental frequency (fo) in the two horizontal directions, and the relationship between the peak values describing the motion of the church and the elevation in which the seismic receivers were installed. Finally, an interferometric analysis on earthquake data recorded by accelerometers returns an estimate of the average shear wave velocity inside the structure.

Only after the evaluation of the suitability of piezoelectric accelerometers, a more specific study can follow in order to search long-term variation of the modal/structural parameters. Indeed our analysis refers to a specific time-period in which safety and confinement elements were installed in the church. The analysis of changes with time of the elastic characteristics of building, or detecting damages from these changes [Pandey and Biswas 1994; Doebling et al. 1998] are not goals of this paper.

\section{Building description}

Santa Maria del Suffragio (or Anime Sante) church was built after the destructive earthquake of 1703. The structure (Figure 1) has a Latin cross plan consisting of a barrel-vaulted nave and side chapels, culminating in a rectangular apse. The architectural composition presents large pilasters, high trabeation and the barrel vault with lunettes. The rectangular system of the structure is dominated by Valadier's dome (XIX century).

The 2009 mainshock caused damage mechanisms in the apse and façade, and the dome of the church was subjected to a partial collapse (Figures 1 and 2). The element cupola was affected by the failure of the belfry, and by the partial collapse of the cupola's and tambour's walls. The

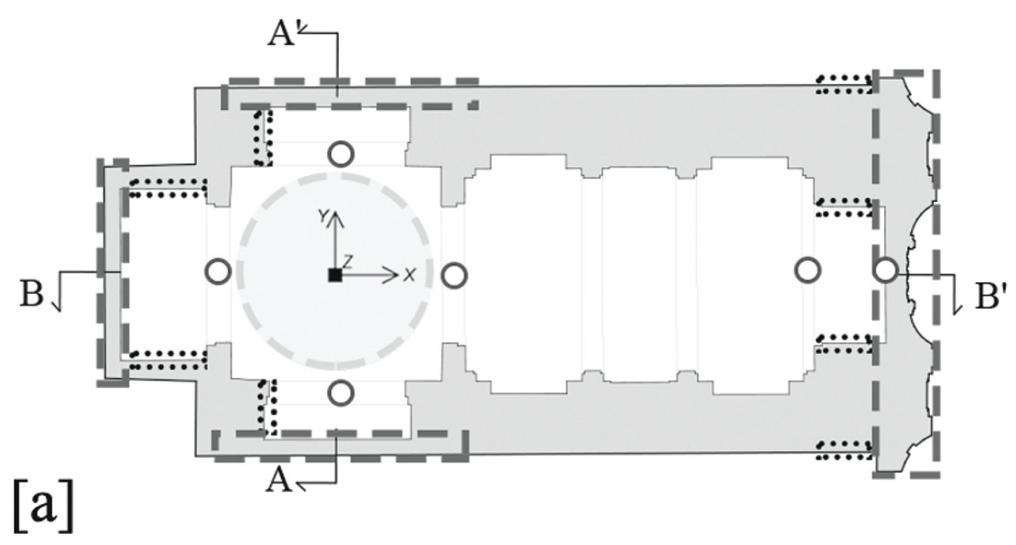

\section{Failure mechanisms}

:::::::: Diagonal crack

○ Crack in keystone

ルニコ Out-of-plane bending

Collapsed dome

Compression crack

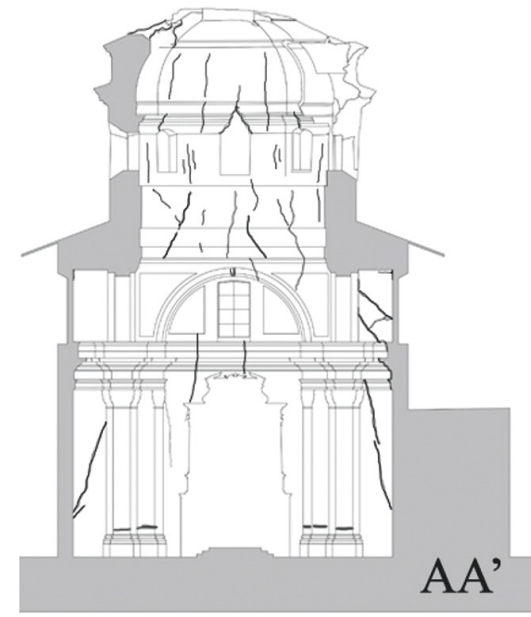

[b]

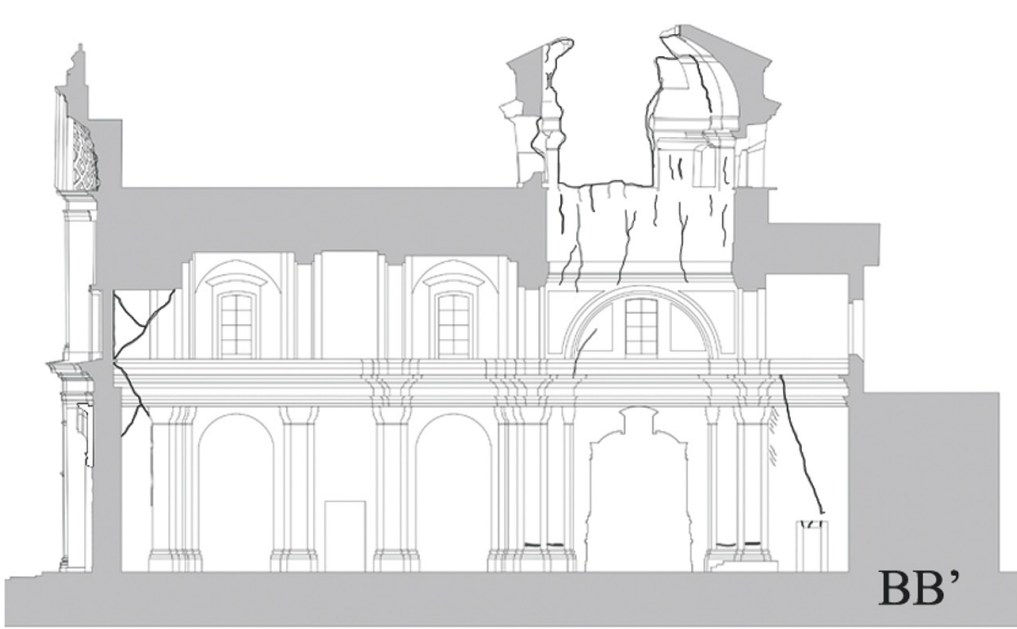

[c]

Figure 1. Some views of Anime Sante Church after the 2009 earthquake; plan scheme of the failure mechanisms (a), transverse (b) and longitudinal (c) section with crack pattern. 

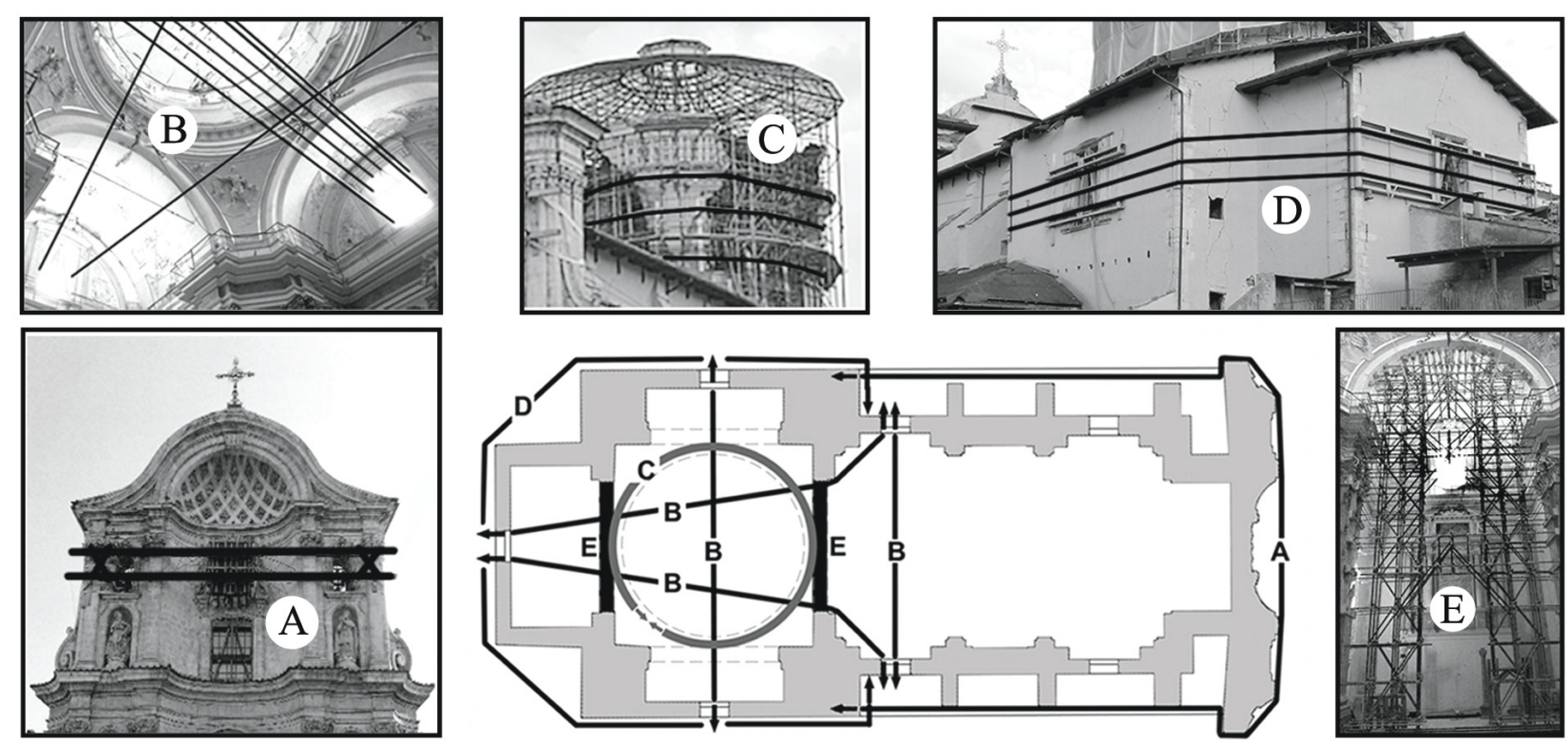

Figure 2. General scheme of the safety measures; linear ties for façade (A) and for transept-nave-apse walls (B and D); scaffold and confinement for tambour (C); scaffolds for apse arch and transept-nave arch (E).

overspread crack pattern, characterized by shear and compression cracks, was arisen by the pendulum movement of the structural element and by the simultaneous collapse of a great part of it. All the arches, the façade, the transept and the apse show cracks at the key zones (Figure 1). The most damaged pillars were those on the side of the apse and of the transept, with vertical cracks related to excessive compression. These elements were also affected by horizontal cracks at 1 meter from floor induced, probably, by the predominant vertical seismic component. The two ties of the transept's arches were visibly damaged during the earthquake. The facade was subjected to a mechanism out of the plane from the nave. After the 2009 mainshock, the church was temporarily reinforced with steel cables and confinement belts (Figure 2), and the collapsed cupola was reconstructed through an octagonal shelter made of steel tubes (Figure 2c). Several sonic tests were carried out on the structural parts of S. Maria del Suffragio church and on similar monuments damaged by L'Aquila earthquake [Boscato et al. 2011]. The retrieved compressional velocity $(\mathrm{Vp})$ shows values in a range between 317 and $487 \mathrm{~m} / \mathrm{s}$.

Within the microzoning activity of the city after the 2009 mainshock [MS-AQ Working Group 2010], a 300 m deep borehole was performed in "Piazza Duomo" square in front of the Santa Maria del Suffragio church. The borehole found the contact between the breccia unit and the lacustrine formation at a depth of $80 / 100 \mathrm{~m}$, whereas available gravimetric survey indicated that the limestone (seismic bedrock) is at a depth of about $300 \mathrm{~m}$.

This deep contact between seismic bedrock and fluvial-lacustrine sediments is responsible of a low-fre- quency subsoil resonance centered at about $0.5 \mathrm{~Hz}$; this resonance characterizes the whole downtown [De Luca et al. 2005; Di Giulio et al. 2014 ].

The 2009 mainshock was recorded by two strongmotion stations (AQU-AQK) situated respectively in the northern and southern downtown [Çelebi et al. 2010]. AQU and AQK are distant from the Anime Sante church 800 and 500 meters, respectively. They recorded similar peak ground values; the peak ground acceleration (PGA) at AQU and AQK was about $0.3-0.35 \mathrm{~g}$ both for horizontal and vertical components [Çelebi et al. 2010].

\section{Dynamic monitoring}

The monitoring activity began in November 2009 and finished in February 2013. The dynamic monitoring system was installed by the research unit of the University of Venice and was based on 28 accelerometric components coupled to a 24-bit data logger (DYMAS24ALBEN multichannel unit; http://www.solgeo.eu). Each channel had its own threshold, calibrated on the signal that is digitalised and pre-elaborated with highpass digital filter, with a cut-off frequency of $0.31 \mathrm{~Hz}$ to remove the sensor's offset. The seismic signals were sampled at $500 \mathrm{~Hz}$ per channel. The dynamic sensors were 19 piezoelectric PCB ${ }^{\circ}$ (http://www.pcb.com) mono-directional accelerometers (model 393C, sensing element quartz) and 3 piezoelectric tri-directional accelerometers (model 356B18, sensing element ceramic) with nominal sensitivity of $1000 \mathrm{mV} / \mathrm{g}$.

The measurement range provided by the product specification is $\pm 2.5 \mathrm{~g}$ for the monoaxial and $\pm 5 \mathrm{~g}$ peak for the triaxial accelerometers. The technical sheets 


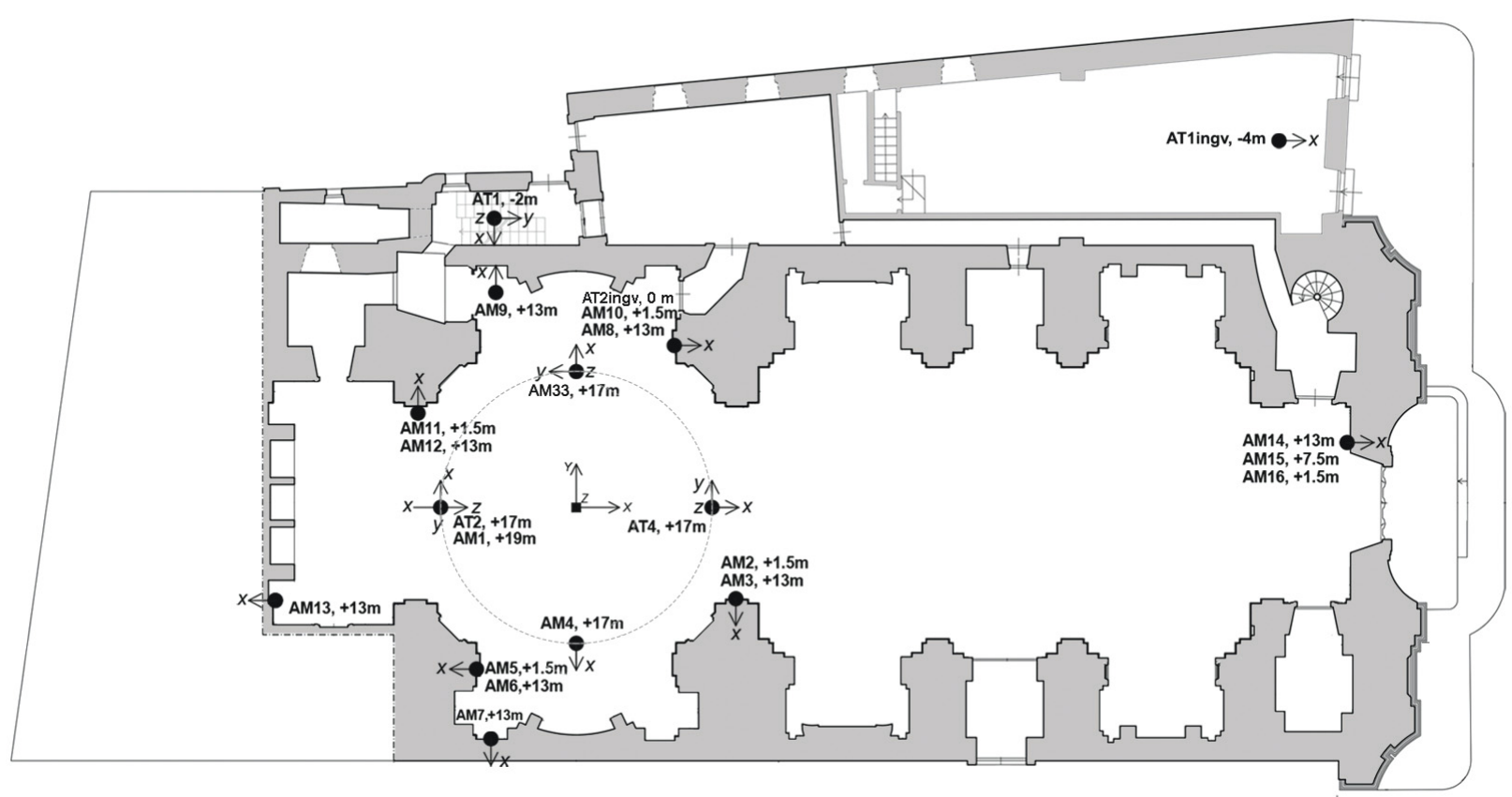

Figure 3. Plan scheme of the accelerometers and velocimeters installed into the church. The longitudinal axis of the church is oriented approximately in a $\mathrm{N}+20$ degree direction (clockwise) with respect to the geographic north.

provide values of spectral noise only for the triaxial accelerometers: $11.4 \cdot 10-6 \mathrm{~g} / \sqrt{\mathrm{Hz}}$ at $1 \mathrm{~Hz}$ and $4 \cdot 10-6 \mathrm{~g} /$ $\sqrt{\mathrm{Hz}}$ at $10 \mathrm{~Hz}$. The manufactured house attests also frequency working interval; from 0.025 to $800 \mathrm{~Hz}$ and from 0.5 to $3000 \mathrm{~Hz}$ for the monoaxial and the triaxial accelerometers, respectively. However the technical specifications refer to high-amplitude signals, and, from the information provided by manufacturers, it is not straightforward to infer the behavior of the piezoelectric accelerometers in case of weaker amplitude signals. Because the triaxial accelerometers have a major full scale in comparison to monoaxial accelerometers, they are expected to show a lower efficacy in resolving lowamplitude waves. Although it is known that these accelerometers have a low sensitivity for ambient-induced vibrations, at the time of installation they were considered appropriate for the structural control of the church during the L'Aquila seismic sequence.

Unfortunately, laboratory tests based on a comparison with a well-known accelerometer under controlled input were not performed for these accelerometers before the monitoring experiment. Because the behavior of the piezoelectric accelerometers is not fully known in case of relatively small magnitude signals, and for the absence of simultaneous recordings of earthquakes between accelerometers and a reference seismic station, a rigorous analysis on the instrumental response [e.g. similar to the one proposed by Clinton and Heaton, 2002] was not possible in this study.

The monitoring system worked in trigger mode and recorded 75000 events composed by human ac- tions (visitors or working activities) and by unknown sources. About 50 earthquakes were also recorded in the monitoring period. In addiction, the stations collected a total of 120 hours of stationary signal in different time periods. In the last period of the monitoring activity, two velocimeters were installed into the church (within the "FIRB-Abruzzo" project in the framework of studies on the local seismic response of the city; http://progettoabruzzo.rm.ingv.it/). The configuration of sensors is illustrated in Figure 3 and Table 1. Mono-directional accelerometers are labeled as AM1, AM2, ...; tri-directional accelerometers are indicated as AT1, AT2 and AT4; the two velocimeters are called $\mathrm{AT} 1_{\text {ingv }}$ and $\mathrm{AT} 2_{\text {ingy }}$. The directions of each sensor after the installation are listed in column \# 2 of Table 1, where $\mathrm{X}$ direction means parallel to the nave, $\mathrm{Y}$ means orthogonal to the nave and $Z$ is the vertical component. We will correct all the data for the direction and polarity according to the XYZ coordinate system indicated in Figure 3 (at the centre of the dome element).

The two seismic velocimeters $A T 1_{\text {ingv }}$ and $A T 2_{\text {ingv }}$, which operated in continuous data acquisition, were installed during the last month of the experiment (from 18 January to 13 February 2013). These seismological stations were composed of a high resolution 24-bit digitizer (Reftek130; www.reftek.com) connected to a three-component velocimeter (Lennartz Le3D-5s; eigenfrequency of $0.2 \mathrm{~Hz}$ and output voltage 400 $\mathrm{V} / \mathrm{m} / \mathrm{s}$; www.lennartz-electronic.de). The sampling rate in data acquisition was fixed to $250 \mathrm{~Hz}$. The power was supplied by external batteries. The UTC time-syn- 

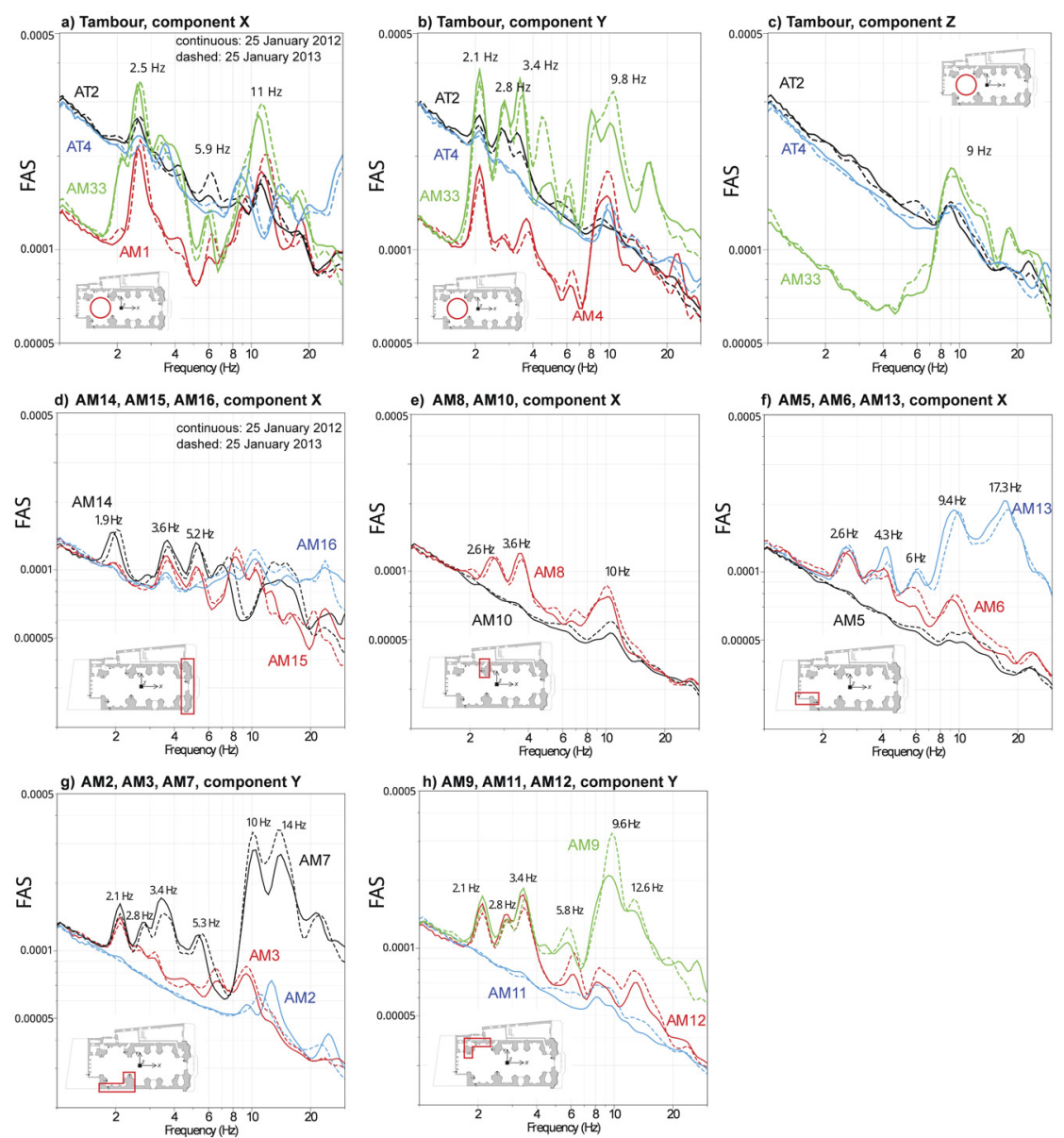

Figure 4. FAS computed on ambient noise data recorded by accelerometers. The time-length of recordings is 1 hour of the 25 January of 2012 and 2013 years (continuous and dashed lines, respectively). The frequency values of the main common spectral peaks are also reported as text into the panels. Units on $\mathrm{y}$-axis are $\mathrm{g} / \mathrm{Hz}$. A small drawing of the sub-set of the displayed sensors is reported in each panel. Panels $\mathrm{a}, \mathrm{b}$ and $\mathrm{c}$ refer to accelerometers located on the tambour (X, Y and $\mathrm{Z}$ component). Panels $\mathrm{d}, \mathrm{e}, \mathrm{f}, \mathrm{g}$ and $\mathrm{h}$ refer to accelerometers located in the remaining structural elements ( $\mathrm{X}$ and $\mathrm{Y}$ component in $\mathrm{d}, \mathrm{e}, \mathrm{f}$ and $\mathrm{g}$, h panels, respectively). The response of AT1, placed at $-2 \mathrm{~m}$ from the ground floor, was not reported because fully dominated by self-noise.

chronism was supplied by a GPS antenna connected to $\mathrm{AT} 1_{\text {ingv }}$, whereas the UTC synchronism was not possible at $\mathrm{AT} 2_{\text {ingv }}$ and the time was provided by the internal clock of the digitizer. AT $1_{\text {ingv }}$ was placed in the refectory nearby the main facade in the underground floor (Figure 3). AT2 $2_{\text {ingv }}$ was placed on the ground-floor of the church near the NW pillar, very close to the accelerometer AM10 (see Figure 3). Naturally the technical characteristics of $\mathrm{AT} 1_{\text {ingv }}$ and $\mathrm{AT} 2_{\text {ingv }}$ give a better resolution in the low-frequency range with respect to the one achieved by the piezoelectric accelerometers.

\section{Ambient noise analysis}

\subsection{Piezoelectric accelerometers}

The dynamic monitoring of the structure is characterized by monoaxial $\left(\mathrm{AM}^{\star}\right)$ and triaxial $\left(\mathrm{AT}^{\star}\right)$ piezoelectric accelerometers. It is important to evaluate the frequency-band in which the system provides suitable response when applied to small-amplitude vibrations (ambient noise and local small magnitude earthquakes).

We firstly analyze the noise data recorded by piezo- electric accelerometers, with the aim to evalutate the behavior of this kind of equipment working with low-amplitude vibrations. We selected two time-windows of seismic noise acquired in the same day (25 of January) of two different years (2012 and 2013). The selected time-windows have the same duration of 1 hour and were processed using the geopsy tools (www.geopsy.org). The Fourier Amplitude Spectra (FAS) were calculated using $40 \mathrm{~s}$ time mobile windows in the frequency range 1-30 $\mathrm{Hz}$. This band includes the most important engineering frequencies in the seismic monitoring of the buildings. For every time window, FASs were smoothed with a Konno and Ohmachi [1998] filter using a coefficient of 40 for the bandwidth. The final mean spectrum and the associated standard deviation were obtained by a geometrical average of the spectra from all windows.

The resulting spectra of the accelerometers on the tambour (AT2, AT4, AM1, AM4 and AM33) are shown in the top panel of Figure 4; they were situated at a height between 17 and $19 \mathrm{~m}$ from the ground floor. The figure evidences different spectral peaks and a complex pattern of resonances along the three directions of motion. The 
a) Tambour, Component $X$
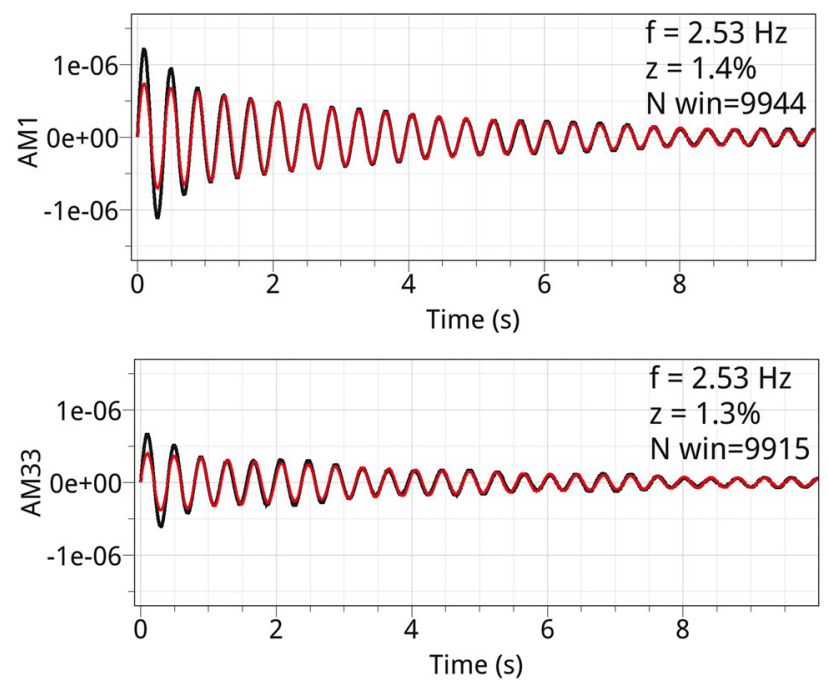

b) Tambour, Component $Y$
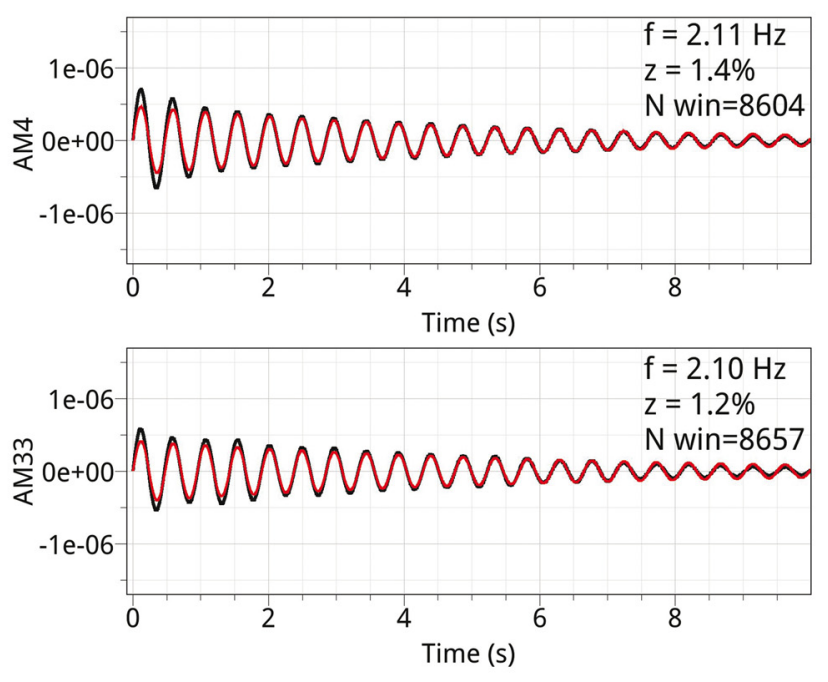

Figure 5. RDM analysis for the accelerometers located on the tambour. The X and Y components are plotted in the panel (a) and (b), respectively. The time-length of recordings is 1 hour (within the day 25 January of 2012). The computed decay curve and the fitting exponentially function are indicated as black and red line, respectively. The resonance frequency ( $\mathrm{f}$ ), the damping ratio ( $\mathrm{z}$ in \%) and the number of selected time-windows from RDM analysis are also indicated in the corner of each plot. Units in the y-axis are arbitrary.

spectra of accelerometers show a main trend decreasing with frequency, where some spectral peaks emerge and indicate the natural vibration periods of the structure. The triaxial stations AT2 and AT4, situated on the tambour, show the lowest signal-to-noise ratio (Fig. 4; panels a,b and c) suggesting a large predominance of station's selfnoise level. The resonance of the fundamental mode ( $\mathrm{f} 0$ ) along the $\mathrm{x}$ - and $\mathrm{y}$-axis is observed at $2.5 \mathrm{~Hz}$ and $2.1 \mathrm{~Hz}$, respectively. The clear peak at $2.5 \mathrm{~Hz}$ on the $\mathrm{x}$ axis (longitudinal direction of the structure) is mostly present at the stations of the tambour and is absent on the y axis, for this reason we associate it to the natural translational resonance along $\mathrm{x}$. For the same consideration, the spectral peak at $2.1 \mathrm{~Hz}$ can be associated to the translational resonance along y (transverse direction of the church). Fig. 4 shows also the FAS computed in the remaining positions of the structure (from panel $\mathrm{d}$ to panel $\mathrm{h}$ ).

Spectral peaks emerge weakly at the stations situated at lower elevation (AM2, AM16, AM10, AM5, AM11 placed at $1.5 \mathrm{~m}$ of elevation from the ground floor), with a consistent increasing of amplitude level in the spectral peaks of the stations at the highest positions.

The FASs of Fig. 4 suggest that the response of piezoelectric accelerometers to seismic noise is not reliable on average below $2 \mathrm{~Hz}$, where the self-noise of the accelerometers is predominant. Similar spectra are obtained by the two recordings separated exactly by one year (January 2012 and January 2013), indicated as continuous and dashed curves in Fig. 4. Although the general consistency between the FAS at a distance of one year, the spectral peaks of the 2013 data show a slight increase in frequency (shift of the order of $0.1 \mathrm{~Hz}$ ) with respect to the spectral peaks of the 2012 data.

This could be explained considering variation with time i) of the input motion, or ii) under the white noise assumptions, of some changes of the structural properties, where an increase of fo could correspond to an increase of stiffness. Anyhow the cause of this frequency shift remains unknown, even if studies on the characterization of buildings indicate that the temperature is the most important parameter related to modal frequency variations [Mikael et al. 2013 among many others].

After the evaluation of the natural frequencies of the structure by spectral analysis, the damping ratio can be estimated from noise recordings. The damping ratio is a dimensionless parameter quantifying the energy dissipation of an oscillating system after a disturbance (viscous approximation). It is related to the logarithmic decrement, i.e. the natural $\log$ of the ratio of the amplitudes of two successive oscillations. We apply the random decrement technique [RDM; Cole 1973; Chang 1975] to noise recordings for estimating the damping ratio. The RDM assumes that the dynamic response of a system to a random excitation is composed both of a deterministic component (the free vibration terms) and of a random component (the forced vibration). The RDM is based on averaging many time-windows of fixed length to enhance the deterministic part, and to filter out the random component. With the aim to estimate the damping ratio in correspondence of the resonance frequency of the structure, a band-pass filter was 
applied around the fo value individuated through the spectral analysis.

The filtering was a fourth-order filter around 2.5 and $2.1 \mathrm{~Hz}$ along the $\mathrm{x}$ - and $\mathrm{y}$-direction, respectively. The RDM computation selects all the band-pass filtered windows, of a given length, characterized simultaneously by two conditions: the null displacement and the positive velocity condition. The first condition (null dis- level) and at the ground floor of the church, respectively (see Figure 3).

The response of the two typologies of instruments (velocimeter and piezoelectric accelerometers) shows strong differences in terms of noise time-series and FAS (Figure 6), even considering two instruments installed very close to each other $\left(\mathrm{AM} 10\right.$ and $\left.\mathrm{AT} 2_{\text {ingv }}\right)$. In the lowfrequency range, the spectrum of the accelerometer
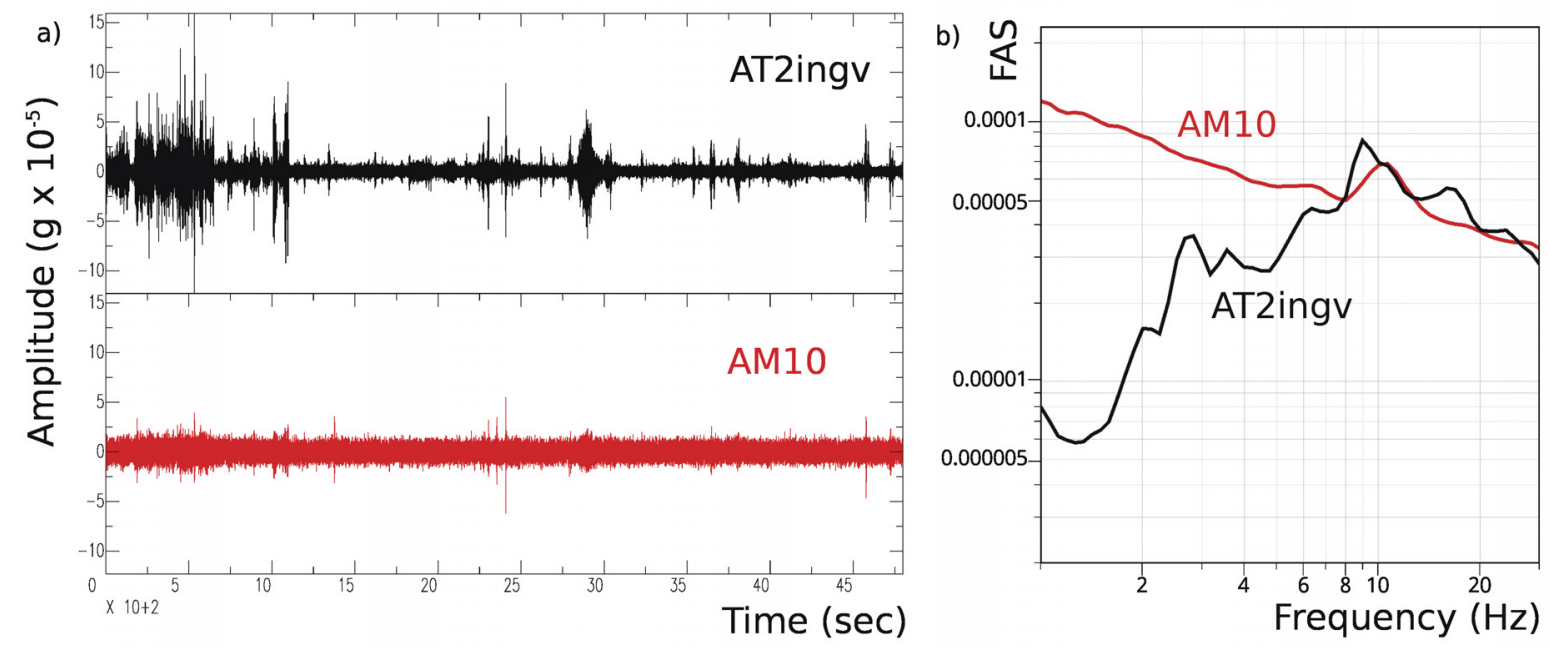

Figure 6. Comparison of simultaneous noise recordings (about one hour, $25^{\text {th }}$ January 2013) between the velocimeter (AT2 ${ }_{\text {ingy }}$, black curves) and the nearby piezoelectric accelerometer (AM10, red curves). The distance between AT2 ${ }_{\text {ingv }}$ and AM10 is $1.5 \mathrm{~m}$ (along the vertical direction, see location in Fig. 3). The comparison is shown in terms of time-histories (a) and FAS (b).

placement) means that the selected time windows start with a 0 amplitude, the second condition (positive velocity) assumes that the windows have a positive derivative. Then the RDM algorithm averages the selected windows, resulting in a free-decay curve related to a positive impulse response. This decay curve is finally fitted by an exponentially decreasing sine function, which is depending on the resonance frequency and the damping ratio. Following the recommendations of Dunand [2005] and Mikael et al. [2013] for obtaining a reliable damping measurement, we used noise time-windows of duration $10 \mathrm{~s}$ and a whole recording of 1 hour, averaging about 9000 segments. The results are given in Figure 5 for the stations situated on the tambour (we show the results of only this element for brevity). The damping ratios of this element show values ranging from $1.2-1.4 \%$.

\subsection{Velocimeters}

The piezoelectric accelerometers cannot provide information in the low-frequency range $(<2 \mathrm{~Hz})$, whereas the three-components velocimeters $\left(\mathrm{AT} 1_{\text {ingv }}\right.$ and $\mathrm{AT} 2_{\text {ingv }}$ ) allow to enlarge the band of investigation at low frequencies up to $0.2 \mathrm{~Hz}$ (eigen-frequency of the Lennartz Le3D-5s velocimeter). AT1 $1_{\text {ingv }}$ and $\mathrm{AT} 2_{\text {ingv }}$ were situated at the underground ( $-4 \mathrm{~m}$ from the floor
AM10 is dominated by self-noise up to $5 \mathrm{~Hz}$ (Figure 6). In the high-frequency band, some spectral peaks common to piezoelectric and velocimeter receivers can be
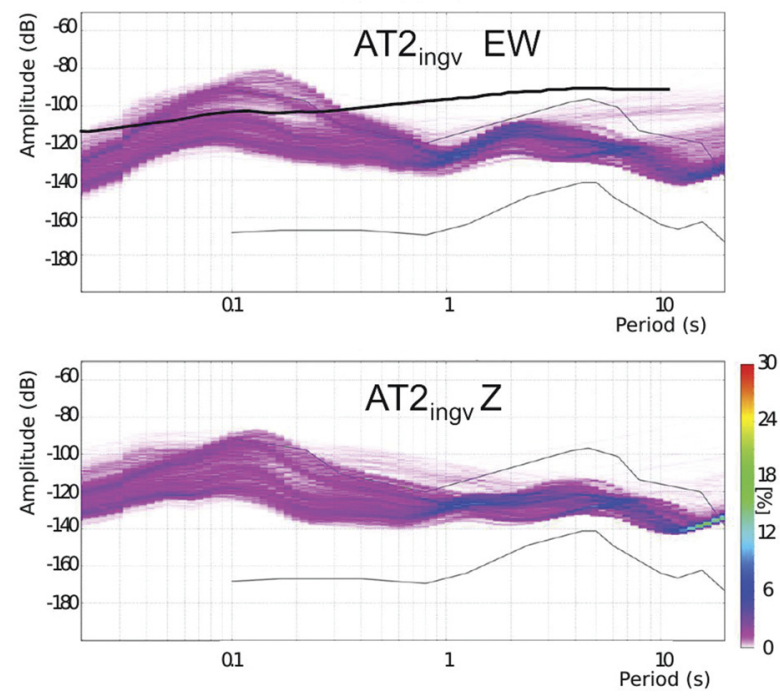

Figure 7. PDFs computed using the PSD curves at AT2 $2_{\text {ingv }}$ (velocimeter) for the EW and vertical component (top and bottom panel, respectively). The PSD curves are related to different onehour segments of the entire recording (from 18 January 2013 to 13 February 2013) and are compared to the Peterson curves (thin black curves). The vertical color bar shows the probability of occurrence. The black thick curve shows the PSD of the piezoelectric accelerometer AM10. The corresponding time-history of AM10 is plotted in Fig. 6a. 

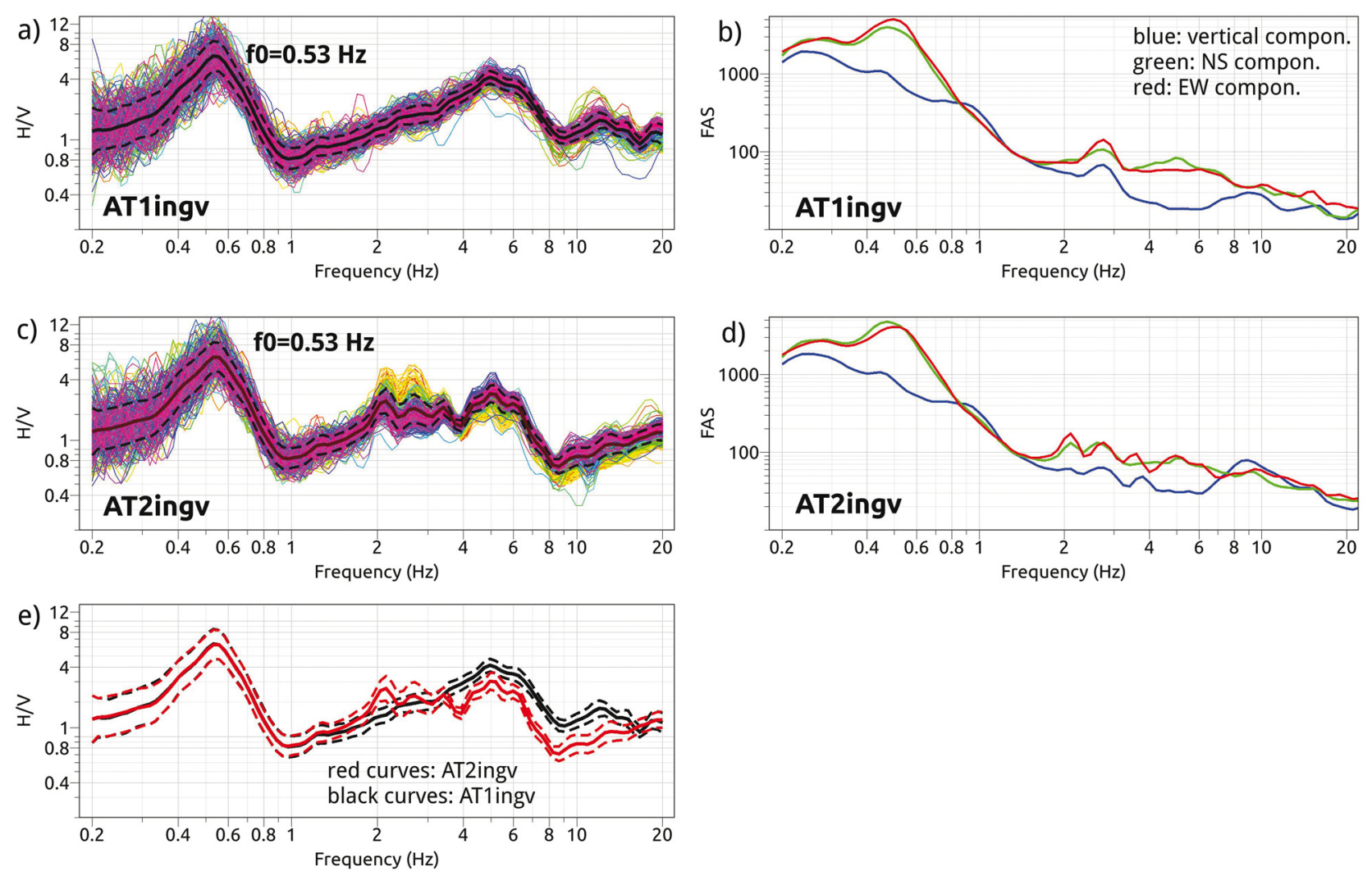

Figure 8. H/V curves at $\mathrm{AT}_{\text {ingv }}$ (a) and AT2 $2_{\text {ingv }}$ (c). The corresponding FASs of the three-components of motions are shown in panel (b) for

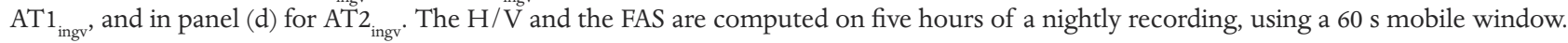
The H/V curves of each single window are plotted in (a) and (c) as colored curve; the black solid and dashed curves show the mean $\mathrm{H} / \mathrm{V}$ and the mean $+/-1$ standard deviation. The value of the resonance frequency (fo) is also indicated. The comparison of the H/V curves between $\mathrm{AT} 1_{\text {ingv }}$ and $\mathrm{AT} 2_{\text {ingv }}$ (mean and mean $+/-1$ standard deviation) is shown in panel (e).

recognized (e.g. at $6 \mathrm{~Hz}$ in the plot of AM10 versus $\mathrm{AT} 2_{\text {ingy }}$ ), but in any case the piezoelectric receiver underestimates the amplitudes of motion. Unfortunately, a simultaneous record of an earthquake was not collected by the accelerometer and the velocimeter. The two typologies of instruments are expected to yield consistent amplitudes in case of larger motion.

The continuous data stream of velocimeters allows to better characterize the level of noise and the frequency content of the experimental data, and to estimate possible bias induced by the cultural activities around the church. In fact the church is placed in the main square ("Piazza Duomo") of downtown L'Aquila, and the activities of reconstruction of some buildings adjacent to the church took place during the time in which $A T 1_{\text {ingv }}$ and $A T 2_{\text {ingv }}$ stations worked. Following McNamara and Buland [2004], we computed the power spectral density (PSD) in order to define a probability density function (PDF) of the seismic noise in the period of investigation. We divided the whole period of recording (about one month) into windows of one-hour long interval, and the Fast Fourier transform was computed on seismic data corrected by instrumental response considering poles and zeros of the sensor. The computation was performed using the routines within the ObsPy project [http:/ / www.obspy.org; Megies et al. 2011]. The PDF of velocimeters was compared in Figure 7 to the new high-noise (NHNM) and to the lownoise (NLMN) Peterson models [Peterson 1993], which are usually assumed as acceptable limits for the seismic noise at inland stations [Bormann 2012]. The PDFs at velocimeters (Figure 7; $\mathrm{AT} 1_{\text {ingv }}$ not shown for sake of simplicity) show noise levels comparable (on the average) to those observed from the Italian inland stations installed in southern Appennine [Vassallo et al. 2012], without any significant spikes or instrumental gaps. The PDFs show a reliable noise level at long-periods at least up to 5 seconds corresponding to the eigen-frequency of the velocimeter. The noise level of the velocimeter sites is on the average below the NHNM curve also at low-periods ( $<1$ second).

Even if we do not have the same data stream recorded contemporaneously by the accelerometer, Figure 7 shows that AM10 (black thick curve) starts to deviate from the noise distribution inferred from the velocimeter data for periods larger than 0.2 seconds. This is consistent with the comparison in terms of FAS illustrated in Figure 6. We can conclude, combining the analysis shown in Fig.s 6 and 7, that the self-noise of piezoelectric accelerometer AM10 (installed in proxim- 

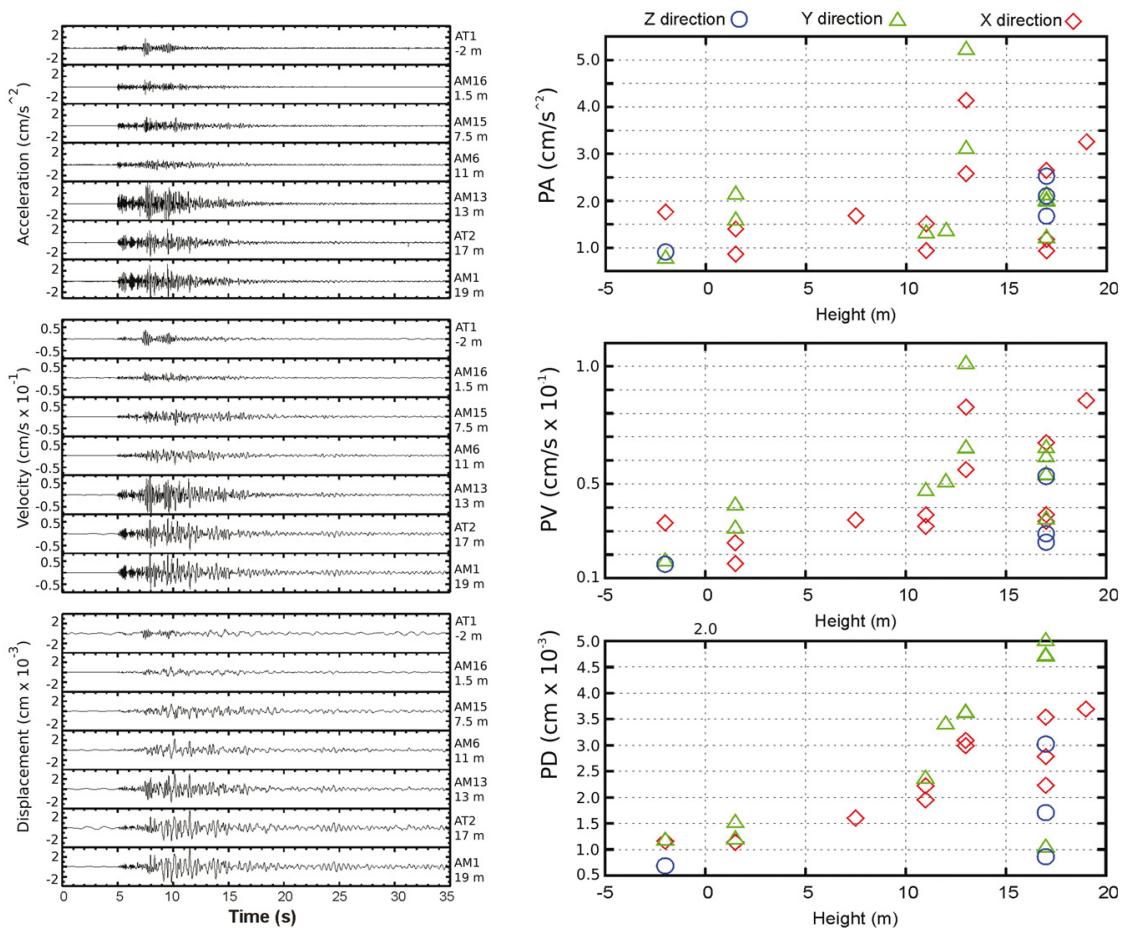

Figure 9a. Earthquake of $30^{\text {th }}$ October 2012 (M 3.6). Left panel: acceleration, velocity and displacement of some stations at increasing elevation (the name of station with elevation is also indicated in the graphs). Right panel: PA, PV and PD versus the station elevation for the three components of motion.

ity of the basement of the church at an elevation of + $1.5 \mathrm{~m}$ ) is very high in the low-frequency range, not providing reliable response to ambient noise vibrations almost below $5 \mathrm{~Hz}$.

Further, the PDFs of the horizontal component of $\mathrm{AT} 2_{\text {ingv }}$ (Figure 7) enhance a maximum level of energy at long periods at about 2 seconds $(0.5 \mathrm{~Hz})$. This peak is absent in the PDF of the vertical component, in agreement with the low-frequency resonance of downtown as evidenced by previous studies [e.g. De Luca et al. 2005]. To evidence clearly this low-frequency amplification, we computed the spectral ratio of the horizontal over the vertical component of ambient noise $(\mathrm{H} / \mathrm{V}$ curve) collected by velocimeters.
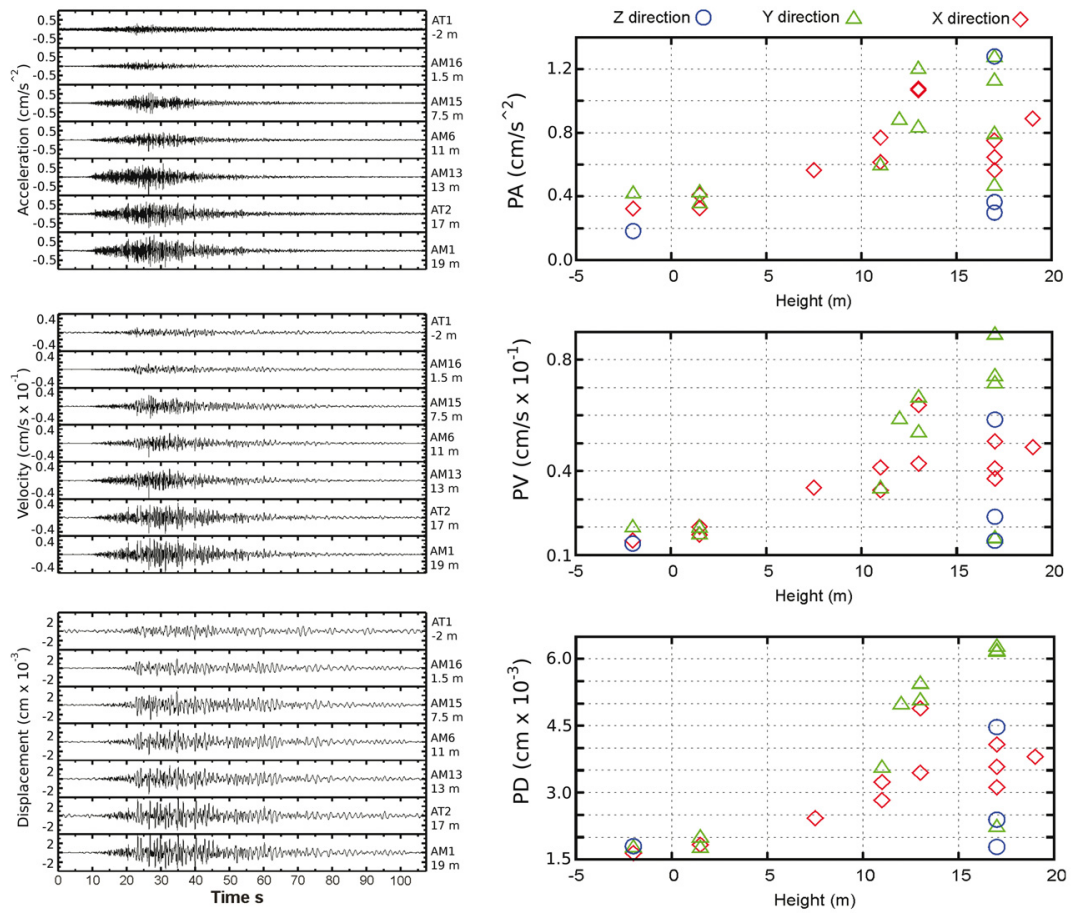

Figure 9b. Earthquake of $16^{\text {th }}$ February 2013 (M 4.8). Left panel: Acceleration, velocity and displacement of some stations at increasing elevation (the name of station with elevation is also indicated in the graphs). Right panel: PA, PV and PD versus the station elevation for the three components of motion. 


\begin{tabular}{|c|c|c|c|}
\hline Sensor & Direction & Height (m) & Position \\
\hline AT1X & $\mathrm{Y}$ & -2 & Transept NW wall \\
\hline AT1Y & $\mathrm{X}$ & -2 & Transept NW wall \\
\hline AT1Z & $Z$ & -2 & Transept NW wall \\
\hline AT2X & $\mathrm{Y}$ & +17 & Tambour \\
\hline AT2Y & $Z$ & +17 & Tambour \\
\hline AT2Z & $\mathrm{X}$ & +17 & Tambour \\
\hline AT4X & $\mathrm{X}$ & +17 & Tambour \\
\hline AT4Y & $\mathrm{Y}$ & +17 & Tambour \\
\hline AT4Z & $Z$ & +17 & Tambour \\
\hline AM33X & Y & +17 & Tambour \\
\hline AM33Y & $\mathrm{X}$ & +17 & Tambour \\
\hline AM33Z & Z & +17 & Tambour \\
\hline AM1 & $\mathrm{X}$ & +19 & Tambour \\
\hline AM2 & $\mathrm{Y}$ & +1.5 & Pillar SE, nave side \\
\hline AM3 & $\mathrm{Y}$ & +11 & Pillar SE, nave side \\
\hline AM4 & $\mathrm{Y}$ & +17 & Tambour \\
\hline AM5 & $\mathrm{X}$ & +1.5 & Pillar SE, apse side \\
\hline AM6 & $\mathrm{X}$ & +11 & Pillar SE, apse side \\
\hline AM7 & Y & +13 & Transept SE wall \\
\hline AM8 & $\mathrm{X}$ & +11 & Pillar NW, nave side \\
\hline AM9 & $\mathrm{Y}$ & +13 & Transept NW wall \\
\hline AM10 & $\mathrm{X}$ & +1.5 & Pillar NW, nave side \\
\hline AM11 & Y & +1.5 & Pillar NW, apse side \\
\hline AM12 & $\mathrm{Y}$ & +12 & Pillar NW, apse side \\
\hline AM13 & $\mathrm{X}$ & +13 & Apse wall \\
\hline AM14 & $\mathrm{X}$ & +13 & Façade \\
\hline AM15 & $\mathrm{X}$ & +7.5 & Façade \\
\hline AM16 & $\mathrm{X}$ & +1.5 & Façade \\
\hline AT1X $X_{\text {ingv }}$ & $\mathrm{X}$ & -4 & Refectory \\
\hline AT1Y ${ }_{\text {ingv }}$ & $\mathrm{Y}$ & -4 & Refectory \\
\hline $\mathrm{AT} 1 Z_{\text {ingv }}$ & $Z$ & -4 & Refectory \\
\hline AT2X $X_{\text {ingv }}$ & $\mathrm{X}$ & 0 & Pillar NW, nave side \\
\hline AT2 $Y_{\text {ingv }}^{\text {ingv }}$ & $\mathrm{Y}$ & 0 & Pillar NW, nave side \\
\hline AT2Z & Z & 0 & Pillar NW, nave side \\
\hline
\end{tabular}

Table 1. List of sensors used in this study. Column \#3 shows the height of the installation. The codes $\mathrm{AT}^{\star}$ and $\mathrm{AM}^{\star}$ indicate the monoand tri- axial accelerometers, respectively. $\mathrm{AT}_{\text {ingv }}$ and $\mathrm{AT} 2_{\text {ingv }}$ indicate the two Reftek-130 digitizers coupled to Lennartz Le3D-5s seismometer.

The single-station $\mathrm{H} / \mathrm{V}$ technique is largely used in site effects studies [Bonnefoy-Claudet et al. 2006], and applications are also possible in building response studies [Mucciarelli et al. 2004; Parolai et al. 2005; Gallipoli et al. 2010; Herak 2011], even if the suitability of the $\mathrm{H} / \mathrm{V}$ method in building analysis is still debatable. The $\mathrm{H} / \mathrm{V}$ ratios of $\mathrm{AT} 1_{\text {ingv }}$ and $\mathrm{AT} 2_{\text {ingv }}$ clearly show the soil resonance at $0.5 \mathrm{~Hz}$ (Figure 8 ) related to the deep structure of the geological model [Di Giulio et al. 2014]. The $\mathrm{H} / \mathrm{V}$ analysis shows secondary peaks also in the high- frequency range $(2-6 \mathrm{~Hz})$. The $5 \mathrm{~Hz}$ peak is common at both stations (Fig. 8e), and from the available geological information it is likely related to a shallow impedance contrast in the uppermost $20 \mathrm{~m}$ of the near-surface geology. According to Del Monaco et al. 2013, this seismic contrast is associated to the presence of shallow anthropic filling or altered breccias overimposed to stiffer breccias. It is worth noting that $\mathrm{AT} 2_{\text {ingv }}$, which is placed on the ground floor of the structure near the NW pillar, shows FAS (Figure 8d) and H/V (Figure 8c) curves with a multitude of anomalous peaks within 2-4 Hz indicating an effect, in this frequency range, of the resonance modes of the structure.

\section{Earthquakes analysis}

\subsection{Peak values and time-frequency analysis}

Two local earthquakes recorded by the piezoelectric accelerometers were analyzed. The two earthquakes have magnitude 3.6 and 4.8 , and occurred the 30 October 2012 (source UTC time 01:52:30) and the 16 February 2013 (21:16:09), respectively. The M 3.6 earthquake was located northwest to L'Aquila city at an epicentral distance of $11 \mathrm{~km}$, the M 4.8 event was located south of L'Aquila (Sora region) at a distance of about $70 \mathrm{~km}$. Both the earthquakes occurred when the safety measures (ties and confinement belts; see Fig. 2) were already in place along the church. The motion parameters were computed for the peak acceleration (PA), velocity (PV) and displacement (PD). The original data were converted from acceleration to velocity and to displacement through a removal of the baseline, a single and double integration, respectively, and applying a 0.1 $\mathrm{Hz}$ high-pass filter using the sac2000 code [Goldstein and Snoke 2005]. Due to the absence of low-frequency content in the recordings of piezoelectric accelerometers, no further corrections were needed in the double integration [Boore 2005]. The time histories of the two earthquakes are shown in Fig.s 9a and 9b. The PA, PV and PD are also plotted as function of the elevation of the sensors. Fig.s 9a and 9b evidence an increasing trend of peak values with the height, according to the modal superposition. The increasing trend is more clear for the PD, which is a parameter more related to the low-frequency content of the motion. The PD trend shows larger amplitude along the $y$ - rather than the $\mathrm{x}$-axis, being the $\mathrm{y}$-axis the shortest side of the church. The stations on the tambour were situated at a height of $17 \mathrm{~m}$ (Table 1), and the distribution of the peak values at $+17 \mathrm{~m}$ deviates from the general trend for both the earthquakes (see Fig.s 9a and $9 \mathrm{~b}$ ). For accelerometers installed on the tambour, the PA and PV behavior versus height seems depending on the earthquake. In fact PA and PV distributions are very 


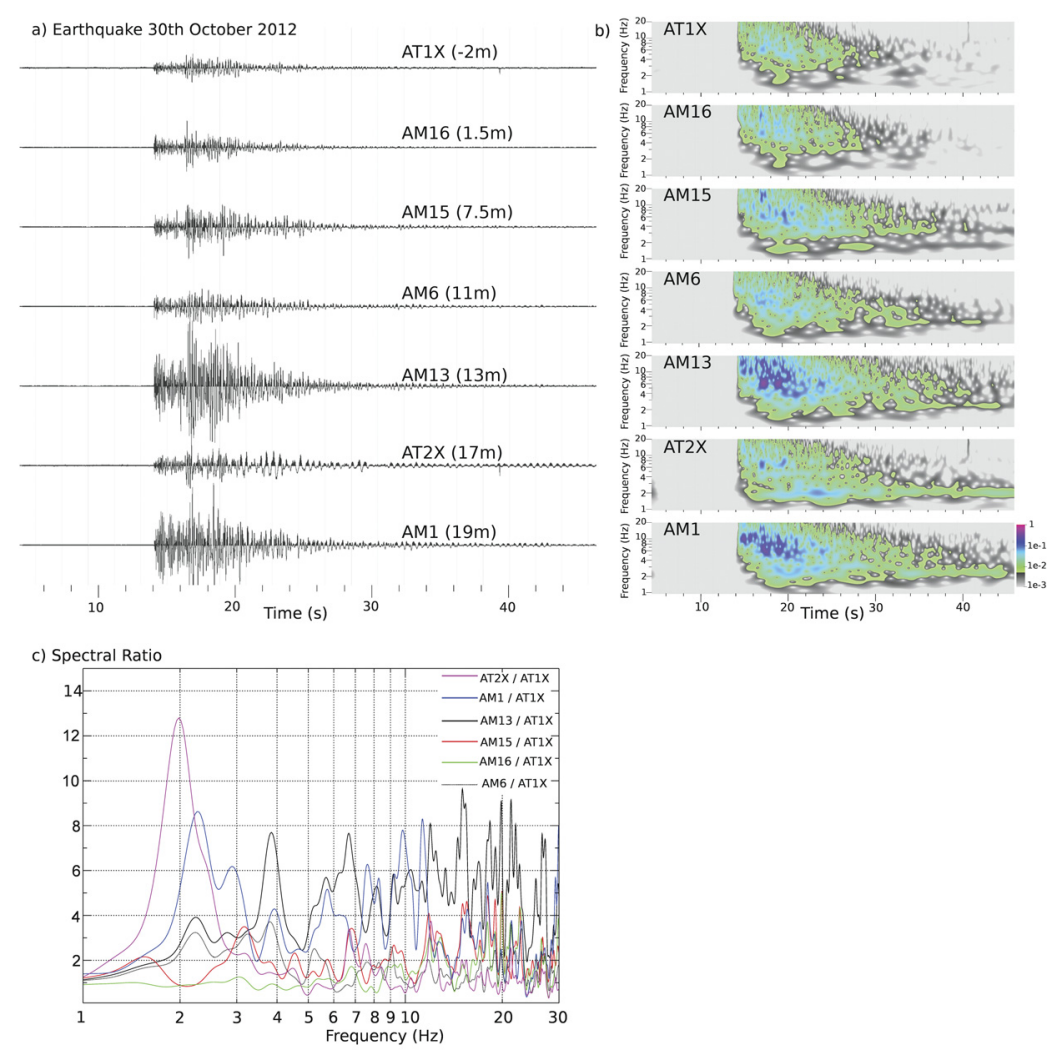

Figure 10. Acceleration of the M 3.6 earthquake of $30^{\text {th }}$ October 2012 (see also Fig. 9a); the time series are scaled at the same y-amplitude. b) Time-frequency analysis. c) Spectral ratio of the time-series shown in panel (a), assuming as reference site the station AT1X.

close and spread in the case of M 3.6 and M 4.8 earthquake, respectively. This could be related to the frequency content of the seismic input, with the M 4.8 earthquake more distant than the M 3.6 event. As a consequence, the corresponding seismic recordings are poor in high frequencies and then more biased by the self-noise of the accelerometers.

However for both the earthquakes, the stations on the tambour show an unexpected trend, with amplitudes lower than the ones of the stations placed at similar height. The behavior of the stations installed in the heavy damaged tambour, in terms of peak values, is not easy to explain, considering also that the motion at the fundamental frequencies $(2.1$ and $2.5 \mathrm{~Hz}$ in the transverse and longitudinal directions) is in phase with the church oscillating as a whole. A specific multi-modal analysis, which includes the complexities connected to the presence of the safety confinements and of the octagonal shelter of steel tubes, is out of the purpose of this paper.

A reliable tool to highlight the structural resonances is also represented by time-frequency analysis. Time-frequency analysis is of course more reliable than Fourier analysis when the structure exhibits a non-stationary time-varying behavior, as induced by forced vibrations or strong earthquakes [Mucciarelli et al. 2004; Ditommaso et al. 2012]. The spectrogram of the M 3.6 earthquake is shown in Fig. 10. The time-fre- quency analysis is based on the use of wavelet mother functions to follow the energetic frequency variation within the signals, with a good compromise on resolution in time- and frequency- domain [Combes et al. 1989]. The selected mother signal was a Morlet wavelet [Morlet et al. 1982] with a length of about $1 \mathrm{~s}$. The modal frequencies are very clear from the time-frequency analysis especially in the coda (Fig. 10b), and are consistent with the ones resulting from FAS analysis.

The fundamental mode is visible around $2 \mathrm{~Hz}$, and the accelerometers installed in the uppermost position show the strongest and largest duration of the resonance (Fig. 10b). The classical spectral ratio for this earthquake was also computed assuming AT1X (placed at $-2 \mathrm{~m}$ ) as reference station, and consistently with the time-series, the maximum amplitudes of the ratio are observed at the stations situated at the highest elevations (Fig. 10c). The spectral ratio shows a complex response of the structure, with a significant dependence of the magnified frequencies with height and position of the accelerometers.

\subsection{Interferometric analysis}

Finally, we performed a cross-correlation analysis by using the two earthquakes. Following the interferometric approach proposed by Snieder and Şafak [2006], we considered seismic signals recorded at different 
a L'Aquila 30-10-2012, 1-3 Hz

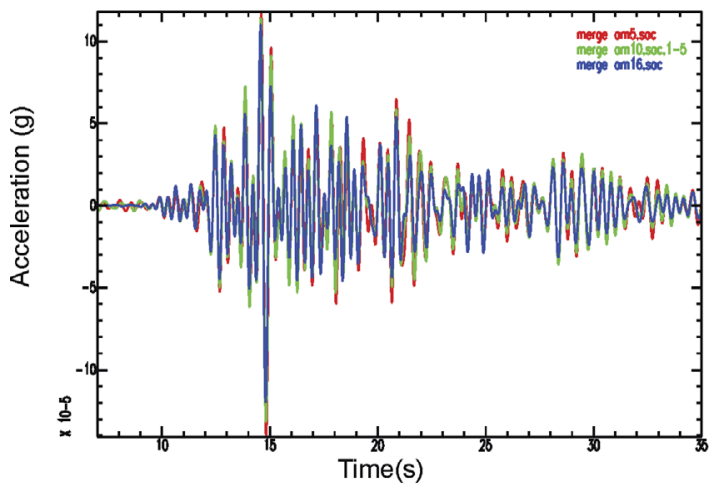

C

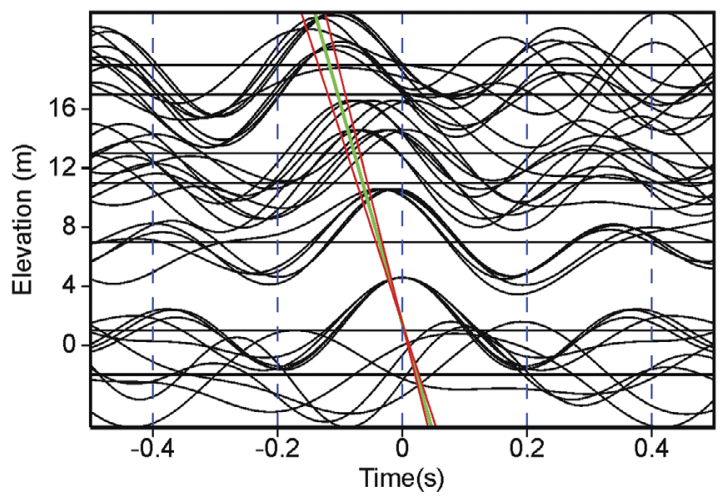

b Frosinone $16-02-2013,1-3 \mathrm{~Hz}$

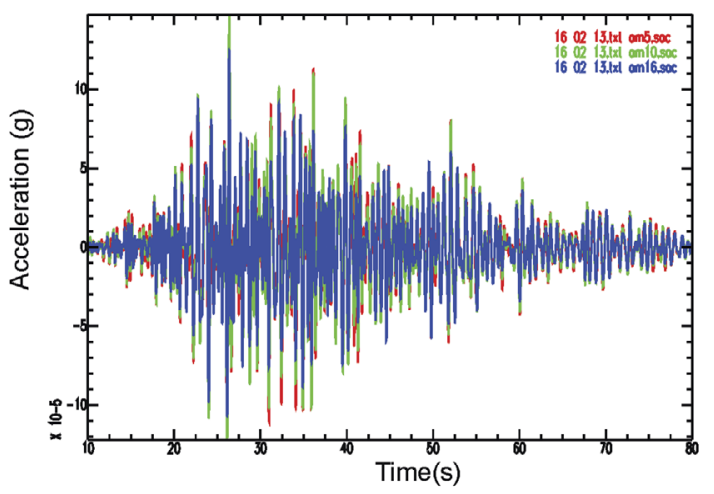

d

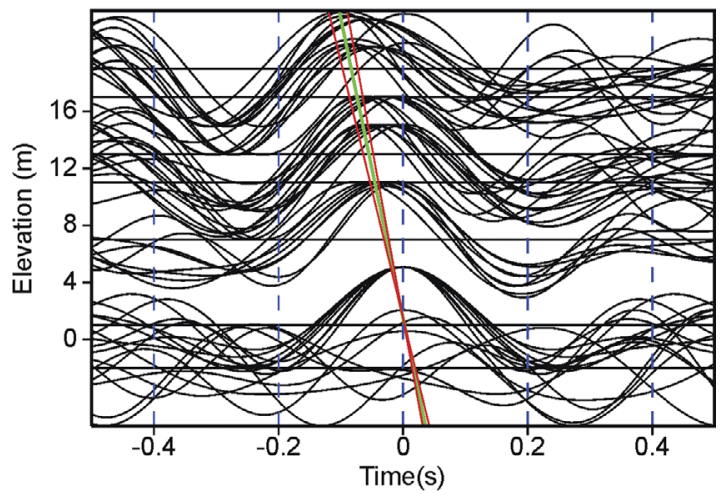

Figure 11. Comparison of the signals acquired by three accelerometers (x components; AM5, AM10 and AM16) installed at $1.5 \mathrm{~m}$ height for the M 3.6 (a) and the M 4.8 (b) event. The signals are filtered in the 1-3 Hz frequency band. The results of interferometric analysis performed using the sensor AM16 as reference for both events are shown in (c) and (d). The cross-correlation signals are normalized for the maximum trace value and are organized according to the height of accelerometers. The slope of the green line (in absolute value) is equal to the shear wave velocity estimated by the picks of the maximum of positive pulses. The thin red lines represent the estimated uncertainties of velocities.

building levels respect to a signal at a reference level [Bindi et al. 2014].

The cross-correlation analysis was performed using the $\mathrm{x}$ horizontal component of the seismic records, this because the stations are more spread out at the different elevations along the $\mathrm{x}$ component rather than along the other components. The signal recorded at AM16 (installed at $1.5 \mathrm{~m}$ of height on the facade) was assumed as reference for the computation of the crosscorrelation functions, due to the lack of accelerometers located at the base ( $0 \mathrm{~m}$ of height) of the church. As suggested by Picozzi et al. [2011], we repeated the interferometric analysis with a sliding, non-overlapping window of $3 \mathrm{~s}$ width for the M 3.6 earthquake, and of $5 \mathrm{~s}$ width for the M 4.8 earthquake. The first window starts with the first arrival of P-wave for both the events. Based on the duration of the two events, the cross-correlation has been computed on a number of 5 and 8 windows for the M 3.6 and M 4.8 events, respectively.

The signals used for the analysis were acquired by stations not installed along the same vertical line. To overcome this problem, we performed the analysis on filtered data between 1 and $3 \mathrm{~Hz}$ around the resonant frequency. In this band the wavelength of seismic sig- nal is large enough to ensure that the signal recorded at $1.5 \mathrm{~m}$ (used as reference) is independent from the stations location in the horizontal plane. Fig.s 11a and 11b show, for both the events, the accelerometric recordings ( $x$ components filtered in the $1-3 \mathrm{~Hz}$ band) at three stations situated at a similar height of $1.5 \mathrm{~m}$ (AM5, AM10 and AM16).

In this frequency band, the three signals recorded in different points of the church appear very similar to each other, both in amplitudes and in phases. The crosscorrelation functions computed for each analyzed window have been organized according to the elevation of the stations. The cross-correlations results (Fig.s 11c and 11d) indicate clear coherent wave propagation, except for the accelerometer AT1 situated at $-2 \mathrm{~m}$. By picking the maximum of the positive pulses for the different stations heights, we retrieved the shear wave velocity inside the structure. The velocity is computed performing a linear regression between the picked time-shifts and the corresponding sensor's heights. The shear velocities were estimated using an implementation of the nonlinear leastsquares (NLLS) Marquardt-Levenberg algorithm. The estimated velocities of the shear deformation are $150( \pm 20)$ and $210( \pm 30) \mathrm{m} / \mathrm{s}$ for the M 3.6 and M 4.8 events, re- 
spectively. The difference between the two estimates can be explained by the diverse shaking amplitudes of the two events [Picozzi et al. 2011], or by the nonlinear building behavior due to the opening of existing cracks in the church's walls during the earthquakes [Todorovska and Trifunac 2008].

\section{Conclusion}

This paper investigates the limits and potentiality of low-cost piezoelectric accelerometers in the assessment of the seismic response of a damaged historical church, which is situated in downtown L'Aquila. The piezoelectric accelerometers are designed for recording strong signals and the technical information provided by manufacturers usually refers to such context. When strong-amplitude signals are absent, the reliability of piezoelectric accelerometers in recording weaker motion needs to be evaluated in an accurate way. We check the reliability of the monitoring system installed in the church with in-situ low-amplitude data (local earthquakes and ambient noise), applying simple techniques of analysis commonly employed in seismic building characterization. The monitoring system was composed of triaxial and monoaxial piezoelectric accelerometers. Two threecomponents velocimeters extended at low-frequency (eigenperiod 5 seconds) were also added during the last month of monitoring.

From our analysis, the following conclusions may be highlighted:

- For low-amplitude vibrations, the piezoelectric accelerometers do not have resolution below $2 \mathrm{~Hz}$. It is also important to note that the efficacy of the piezoelectric accelerometers is depending on the position of the installation. The piezoelectric accelerometers installed in the underground floor or in proximity of the basement level can be strongly biased by their self-noise. The accelerometers situated at the uppermost elevations are characterized by a greater amplitude of the motion, and show more reliable recordings. As expected the triaxial accelerometers, with a larger full scale, have a higher self noise with respect to the monoaxial accelerometers. An investigation of the signal-to-noise ratio, and the comparison of data recorded simultaneously by piezoelectric accelerometers and well known velocimeters, help in evaluating the reliability of the observed spectral peaks.

- The velocimeters show a strong resonance at 0.5 $\mathrm{Hz}$ at the basement of the church. This corresponds to the subsoil resonance of the deep geological structure of downtown L'Aquila. In according to the previous conclusion, the fo of subsoil at $0.5 \mathrm{~Hz}$ cannot be recognized using the data of the piezoelectric receivers.

- The analysis based on noise and earthquake data shows a complex response of the damaged church. Many spectral peaks are observed and the building motion appears larger along the shortest (y-axis) than the longest ( $\mathrm{x}$-axis) side of the church. The fundamental frequencies are observed around 2 and $2.5 \mathrm{~Hz}$ from the spectral peak analysis.

- The amplitudes of motion is clearly related to the elevation of the receivers located into the structure. According to the modal superposition, the motion at the top of the building is greater than the motion at the bottom. From the selected weak earthquakes, a great frequency dependence of the signal amplitude with height is observed. A relative factor of 10 can be reached between amplitudes recorded at the bottom position and amplitudes recorded at the uppermost position.

- The velocities of the shear waves propagating into the church during two local earthquakes (M 3.6 and 4.8) are estimated by seismic interferometry analysis in about $150-200 \mathrm{~m} / \mathrm{s}$.

The next step is to extend the seismic analysis to a more full data set for characterizing the evolution of building properties throughout the time, within the aims of a structural health monitoring analysis.

Acknowledgements. The authors thank the technical staff of LabSCo (Laboratory of Strength of Materials) of IUAV University of Venice for their support during the installation and monitoring phases. Financial support by the research project AQ DPC/ReLUIS 2014-2018_UR IUAV-DPPAC_RS 4_"Seismic Observatory of Structures \& Monitoring" is gratefully acknowledged by the Authors. G.D.G. and M.V. are financially supported by the Project Firb Abruzzo ("Indagini ad alta risoluzione per la stima della pericolosità e del rischio sismico nelle aree colpite dal terremoto del 6 aprile 2009”, Research Unit \#7, funding code RBAP10ZC8K_007). We thank the editor Francesca Bianco and the anonymous reviewers, their suggestions improve greatly this work. We thank the priest and the clerical staff of the church and Mr. Aureliano for the logistic support.

\section{References}

Bindi, D., B. Petrovic, S. Karapetrou, M. Manakou, T. Boxberger, D. Raptakis, K.D. Pitilakis and S. Parolai (2014). Seismic response of an 8-story RC-building from ambient vibration analysis, Bull Earthq Eng 126, doi 10.1007/s10518-014-9713-y.

Bonnefoy-Claudet, S., C. Cornou, P.Y. Bard, F. Cotton, P. Moczo, J. Kristek and D. Fäh (2006). H/V ratio: a tool for site effects evaluation. Results from 1D noise simulations, Geophys. J. Int., 167(2): 827-837, doi: $10.1111 /$ j.1365-246X.2006.03154.x.

Boore, D.M. (2005). On pads and filters: processing strong-motion data, B. Seismol. Soc. Am., 95(2), 745 750.

Bormann, P. (Ed.) (2012). New manual of seismological observatory practice (NMSOP-2). IASPEI, GFZ German Research Centre for Geosciences, Potsdam; 
http:/ / nmsop.gfz-potsdam.de; doi: 10.2312/ GFZ.NMSOP-2 urn:nbn:de:kobv:b103-NMSOP-2.

Boscato, G., S. Russo and F. Sciarretta (2011). Mechanical performance of very old masonry walls after earthquake assessed by ND testing: the case of l'Aquila, 9th Australasian Masonry Conference, Queenstown, New Zealand, 15th - 18th February 2011.

Boscato, G., D. Rocchi and S. Russo (2012). Anime Sante Church's dome After 2009 L'Aquila earthquake, monitoring and strengthening approaches, Advanced Materials Research 446:3467-3485.

Brandonisio, G., G. Lucibello, E. Mele and A. De Luca (2013). Damage and performance evaluation of masonry churches in the 2009 L'Aquila earthquake, Eng Fail Anal, http: / / dx.doi.org/10.1016/j.engfail anal.2013.01.021.

Çelebi, M., P. Bazzurro, L. Chiaraluce, P. Clemente, L. Decanini, A. De Sortis, W. Ellsworth, A. Gorini, E. Kalkan, S. Marcucci, G. Milana, F. Mollaioli, M. Olivieri, R. Paolucci, D. Rinaldis, A. Rovelli, F. Sabetta and C. Stephens (2010). Recorded motions of the 6 April $2009 \mathrm{Mw}$ 6.3 L'Aquila, Italy, earthquake and implications for building structural damage: overview, Earthquake Spectra, 26(3):651-684, doi:10.1193/1.3450317.

Chang, C.S. (1975). Studies of dynamic characteristics of aeroelastic systems utilizing Randomdec Signatures, NASA CR 13253.

Clinton, J.F. and T.H. Heaton (2002). Potential advantages of a strong-motion velocity meter over a strong-motion accelerometer, Seism Res Lett, 73(3), 332-342.

Cole, H.A. (1973). On-line failure detection and damping measurements of aerospace structures by Random Decrement Signature, NASA CR-2205.

Combes, J.M., A. Grossman and P. Tchamitchian (1989). Wavelets. Time-frequency methods and phase space, Springer, Berlin.

Crawford, R. and H.S. Ward (1964). Determination of the natural periods of buildings, Bull Seismol Soc Am 54:1743-1756.

Del Monaco, F., M. Tallini, C. De Rose and F. Durante (2013). HVNSR survey in historical downtown L'Aquila (central Italy): site resonance properties vs. subsoil model, Eng Geol 158: 34-47, doi: 10.1016/j.enggeo.2013.03.008.

De Luca, G., G. Milana, S. Marcucci and T. Sanò (2005). Evidence of low-frequency amplification in the city of L'Aquila, central Italy, through a multidisciplinary approach including strong and weak motion data, ambient noise, and numerical modeling, B. Seismol. Soc. Am., 95(4):1469-1481.

Di Giulio, G., I. Gaudiosi, F. Cara, G. Milana and M. Tallini, M. (2014). Shear-wave velocity profile and seismic input derived from ambient vibration array measurements: the case study of downtown L’Aquila, Geophys. J. Int., 198(2), 848-866.

Ditommaso, R., M. Mucciarelli, S. Parolai and M. Picozzi (2012). Monitoring the structural dynamic response of a masonry tower: comparing classical and time-frequency analyses, Bull Earthq Eng 10:1221-1235.

Doebling, S.W., C.R. Farrar and M.B. Prime (1998). A summary review of vibration-based damage identification methods, Shock and vibration digest, 30(2), 91-105.

Dunand, F. (2005). Pertinence du bruit de fond sismique pour la caractérisation dynamique et l'aide au diagnostic sismique des structures de génie civil, Doctoral dissertation, Université Joseph-Fourier-Grenoble I.

Galli, P. and R. Camassi (eds) (2009). "Rapporto sugli effetti del terremoto aquilano del 6 aprile 2009”. In: DPC-INGV QUEST Team (http: / / www.mi.ingv.it/ eq/090406/ quest.html), in Italian.

Gallipoli, M.R., M. Mucciarelli, B. Šket-Motnikar, P. Zupancic', A. Gosar, S. Prevolnik, M. Herak, J. Stipcevic', D. Herak, Z. Milutinovic' and T. Olumc'eva (2010). Empirical estimates of dynamic parameters on a large set of European buildings, Bull Earthq Eng 8:593-607, doi 10.1007/s10518-009-9133-6.

Gattulli, V., E. Antonacci and F. Vestroni (2013). Field observations and failure analysis of the Basilica $S$. Maria di Collemaggio after the 2009 L'Aquila earthquake, Eng Fail Anal, http:/ / dx.doi.org/10.1016/j. engfailanal.2013.01.020.

Goldstein, P., and A. Snoke (2005). SAC availability for the IRIS community. Incorporated Institutions for Seismology Data Management Center Electronic Newsletter, 7.

Guidoboni, E. (2009). I terremoti storici dell'area aquilana: Preziose informazioni, con qualche ombra, Geoitalia 28: 30-37.

Herak, M. (2011). Overview of recent ambient noise measurements in Croatiain free-field and in buildings, Geofizika, vol.28.

Konno, K. and T. Omachi (1998). Ground-motion characteristics estimated from spectral ratio between horizontal and vertical components of microtremor, B. Seismol. Soc. Am., 88(1):228-241.

McNamara, D.E. and R.P. Buland (2004). Ambient noise levels in the continental United States, B. Seismol. Soc. Am., 94(4):1517-1527.

Megies, T., M. Beyreuther, R. Barsch, L. Krischer and J. Wassermann (2011). ObsPy-What can it do for data centers and observatories?, Annals Of Geophysics, 54(1), 47-58.

Michel, C., P. Guéguen and P.Y. Bard (2008). Dynamic parameters of structures extracted from ambient vi- 
bration measurements: An aid for the seismic vulnerability assessment of existing buildings in moderate seismic hazard regions, Soil Dyn Earthq Eng 28:593-604.

Mikael, A., P. Gueguen, P.Y. Bard, P. Roux and M. Langlais (2013). The Analysis of Long-Term Frequency and Damping Wandering in Buildings Using the Random Decrement Technique, B. Seismol. Soc. Am., 103(1), 236-246.

Morlet, J., G. Arens, E. Fourgeau and D. Giard (1982). Wave propagation and sampling theory, part II. Sampling theory and complex waves, Geophysics 47(2):222-236. doi:10.1190/1.1441329.

MS-AQ Working Group (2010). "Microzonazione sismica per la ricostruzione dell' area aquilana". In: Ed. Regione Abruzzo- Dipartimento della Protezione Civile, pp. 1-796, 3 vol \& CD-rom, in Italian.

Mucciarelli, M., A. Masi, M.R. Gallipoli, P. Harabaglia, M. Vona, F. Ponzo and M. Dolce (2004). Analysis of RC building dynamic response and soil-building resonance based on data recorded during a damaging earthquake (Molise, Italy, 2002), B. Seismol. Soc. Am., 94(5), 1943-1953.

Pandey, A.K. and M. Biswas (1994). Damage detection in structures using changes in flexibility, Journal of sound and vibration, 169(1), 3-17.

Parolai, S., A. Facke, S.M. Richwalski and L. Stempniewski (2005). Assessing the vibrational frequencies of the Holweide Hospital in the city of Cologne (Germany) by means of ambient seismic noise analysis and FE modelling, Nat Hazards 34:217-230.

Peterson, J. (1993). Observations and modeling of seismic background noise. U.S. Geological Survey openfile report 93-322, Albuquerque, N.M., http: / / ehp3 earthquake.wr.usgs.gov/regional/asl/pubs/files/of r93-322.pdf.

Picozzi, M., S. Parolai, M. Mucciarelli, C. Milkereit, D. Bindi, R. Ditommaso, M. Vona, M.R. Gallipoli and J. Zschau (2011). Interferometric analysis of strong ground motion for structural health monitoring: the example of the L'Aquila, Italy, seismic sequence of 2009, B. Seismol. Soc. Am., 101(2): 635-651.

Russo, S. (2012). On the monitoring of historic Anime Sante church damaged by earthquake in L'Aquila. Struct Control Health Monit, published online in Wiley Online Library (wileyonlinelibrary.com), doi: $10.1002 /$ stc. 1531.

Russo, S. (2013). Testing and modelling of dynamic outof-plane behaviour of the historic masonry façade of Palazzo Ducale in Venice, Italy, Eng Struct 46:130- 139, doi: 10.1016/j.engstruct.2012.07.032.

Snieder, R. and E. Şafak (2006). Extracting the building response using interferometry: theory and applica- tions to the Millikan Library in Pasadena, California, B. Seismol. Soc. Am., 96(2):586-598.

Tertulliani, A., L. Arcoraci, M. Berardi, F. Bernardini, R. Camassi, C. Castellano, S. Del Mese, E. Ercolani, L. Graziani, L. Leschiutta, A. Rossi and M. Vecchi (2011). An application of EMS98 in a medium-sized city: The case of L'Aquila (central Italy) after the April6, 2009 Mw 6.3 earthquake, Bull Earthq Eng 67-80, doi:10.1007/s10518-010-9188-4.

Todorovska, M.I. and M.D. Trifunac (2008). Impulse response analysis of the Van Nuys 7-storey hotel during 11 earthquakes and earthquake damage detection, Struct Control Health Monit 15: 90-116, doi: $10.1002 /$ stc. 208 .

Trifunac, M.D. (1972). Comparisons between ambient and forced vibration experiments, Earthq Eng Struct Dyn 1:133-150.

Vassallo, M., G. Festa and A. Bobbio (2012). Seismic ambient noise analysis in Southern Italy, B. Seismol. Soc. Am., 102(2):574-586, doi: 10.1785/0120110018.

\footnotetext{
${ }^{\star}$ Corresponding author: Giuseppe Di Giulio, Istituto Nazionale di Geofisica e Vulcanologia, L’Aquila, Italy; email: giuseppe.digiulio@ingv.it.

C 2014 by the Istituto Nazionale di Geofisica e Vulcanologia. All rights reserved.
} 